\title{
Research on CPA Auditing Reform Strategy Under the Background of Artificial Intelligence
}

\author{
Jianhua $\mathrm{Luo}^{1}$, Zhirong $\mathrm{Hu}^{2 *}$, Luo Wang ${ }^{3}$ \\ 1,2 Associate Professor, 3 Teaching Assistant ,Institute of Finance and Economics, Chongqing College of Electronic Engineering, \\ Chongqing, 401331
}

\begin{abstract}
With the rapid development of artificial intelligence, big data and cloud computing, especially the development and application of financial intelligent robots, the accounting and auditing industries are facing unprecedented challenges. Many past predictions about artificial intelligence have turned into realities. As accountants and auditors, what they need to think carefully is that where are the accounting and auditing heading for in the context of artificial intelligence (AI), cloud computing and big data ("smart. cloud. data" for short). This paper aims to analyze the aspects and logical relations of the influence that artificial intelligence have on accounting and auditing under the background of the development of new technology based on artificial intelligence, and to design and propose the reform strategies for accounting firms (CPAs), thus to provide valuable decision-making references for auditing changes of accounting firms (CPAs).
\end{abstract}

Keywords-Artificial intelligence; CPA audit; Reform; Strategy

\section{INTRODUCTION}

The term "Artificial Intelligence" (AI) was first proposed at the Dartmouth Society in 1956. It is a new technical science that studies and develops the theory, method, technology and application system for simulating, extending and expanding human intelligence. It also tries to understand the essence of intelligence and produce a new intelligent machine that can respond in a similar way to human intelligence. Artificial intelligence is the simulation of the information process of human consciousness and thinking. And artificial intelligence is not human intelligence, but it can think like a human and can be infinitely close to human intelligence.

Since the rise of artificial intelligence in the 1950s, artificial intelligence has been widely used in language processing, automatic theorem verification, computational intelligence, intelligent data retrieval systems, vision systems, problem solving, disease diagnosis, and space aircraft and underwater robots control. Especially in the past one or two years, AI has developed rapidly, Li Shishi who is defeated by the AlphaGo and the advent of driverless cars has made AI a hot topic in the world. Additionally, the Financial Times predicted that by the end of the last century, $70 \%$ of the occupations we are familiar with were replaced by automation technology, and robots would become human's colleagues. Today, the impact of artificial intelligence on all walks of life is even more fierce and profound and many past prophecies about artificial intelligence have been and are becoming a reality.

\section{THE MAIN INFLUENCE OF ARTIFICIAL INTELLIGENCE ON ACCOUNTING}

Artificial intelligence has a huge impact on all walks of life, with the accounting industry particularly affected.

According to a survey by The Economist magazine in 2014 jobs that are most likely to be replaced by robots in the next 20 years including low-end manufacturing, sales, and accounting.

Also, a recent study by the University of Oxford in the UK shows that $35 \%$ of jobs in the UK are likely to face the risk of being replaced by automation in the next 20 years, such as insurance underwriters, tax agents, loan officers, credit analysts, and accounting professionals.

In the next 10 years, what industry employees may be replaced by artificial intelligence? According to the survey results, the rates of substitution were listed as follows: $2.1 \%$ in medicine, $3.5 \%$ in law, $8.4 \%$ in journalism, 32.7\% in English major, $86 \%$ in real estate, $89.7 \%$ in human resources, $96.5 \%$ in administration, $96.8 \%$ in finance, $97 \%$ in insurance and $97.6 \%$ in accounting.

It can be seen that regardless of the research report, there is always accounting in occupations that are most likely to be replaced by artificial intelligence.

With Deloitte, PricewaterhouseCoopers, Ernst \& Young, and KPMG Big Four Certified Public Accountants unveiling "financial intelligent robots" in 2016 and 2017, RPA technology has been widely used by more and more industries. It has successfully confirmed the rapid development of technology and the advent of a new era of artificial intelligence as well.

To sum up, the impacts of artificial intelligence on accounting are mainly reflected in the following aspects: 


\section{A. Impact on the goals of accounting}

The goal of China's financial accounting is to provide accounting information users with useful information for their decisions, which mainly emphasizes the formation process and the quality of accounting information. While artificial intelligence mainly influences accounting objectives by affecting the process of accounting information generation and the quality of accounting information.

\section{B. Impact on Accounting Objects}

The object of accounting is the movement of funds organized by the enterprise, that is, the various transactions and events occur in the enterprise that can cause changes in the accounting elements. In the highly developed state of artificial intelligence, the majority of corporate behavior exists in the form of "data", and artificial intelligence can automatically identify and filter what belong to the accounting object.

\section{Impact on accounting methods}

Accounting methods include method of accounting, accounting analysis and accounting supervision. With the development of "smart. cloud. data", various accounting methods are highly integrated. They can efficiently conduct accounting, at the same time, facilitate accounting analysis and achieve accounting supervision very well.

\section{Impact on accounting functions}

Basically, accounting has two functions of accounting and accounting supervision. It also includes derivative functions such as forecasting economic prospects, participating in economic decision-making, and evaluating business performance. However, in the traditional accounting environment, the accounting function is the most prominent in both basic functions while supervision function seems to be reduced, and the functions of forecasting, decision making and evaluation are almost hidden. Additionally, under the new conditions of "smart. cloud. data" technology, the accounting and supervision functions of accounting are still basic functions. But, the derivative functions of accounting prediction, decision-making, and evaluation can be strengthened and enhanced, which objectively requires financial personnel to be able to identify economic business, analyze information and maeke decisions. This is also the reason why financial accounting must be transformed into management accounting in the background of artificial intelligence.

\section{IMPACT OF ARTIFICIAL INTELLIGENCE ON AUDITING}

\section{A. The direct impact of Artificial Intelligence on auditing}

The direct impact of artificial intelligence on auditing is mainly reflected in the impact on auditing methods and methods.

Obviously, based on the development of big data, cloud computing, and artificial intelligence, auditing must be conducted through an online paperless auditing platform. With the high efficiency of artificial intelligence, the mainstream sampling audit for a long period of time can return to the detailed audit, then the audit risk is further reduced. In other words, in the context of artificial intelligence, due to the wide use of financial robots, the cost of auditing will be greatly reduced, the efficiency will be greatly improved, the audit quality will be further improved as well, and the auditor only needs to consider the risk management and control. In this way, the procedural behaviors in CPA auditing, such as audit sampling, the collection of audit evidence, and the generation of audit reports, will be gradually replaced by artificial intelligence.

Through investigations, we found that under the background of artificial intelligence, cloud computing and big data, accounting firms also encounter difficulties, mainly manifested in:

The audit idea of auditors is lagging behind, and many accounting firms and CPAs still stick to the traditional auditing.

The infrastructure construction and auditing equipment of accounting firm are backward. Basically, a combination of computer and printer could be used, or auditing system software could be used to simple sampling audits and evidence collection, and compilation of audit working papers, hence, we can see that the level of artificial intelligence is still relatively low.

The auditing skills that adapt to "smart. cloud. data" need to be updated and improved, including the lack of hardware use skills for artificial intelligence auditing and the use of "cloud. data" for audit data screening and data analysis. At present, the CPA auditing skill system mainly consists of determining audit target, compiling audit plan, determining the importance of auditing, assessing audit risk, implementing audit procedures to collect audit evidence, compiling audit manuscript, and evaluating audit evidence and issuing audit report. Besides, many auditors do not know much about artificial intelligence, big data and cloud computing, only auditors who are proficient in finance and are familiar with artificial intelligence, big data and cloud computing technologies can be better qualified for the audit work under the background of new technology.

Under the background of the "smart. cloud. data", how the accounting firm and CPAs perform confidential duties that is also a problem needs to be solved urgently. 


\section{B. Influences of Artificial Intelligence on audit through smart finance (AI Finance)}

We briefly refer to financial operations that fully utilize artificial intelligence as intelligent finance (AI Finance). Clearly, artificial intelligence also influences audits indirectly through accounting changes.

1) Influences of Artificial Intelligence (AI Finance) on the target of audit

The objectives of the audit of the financial statements include the overall objectives and specific audit objectives. From the overall goal of the auditing financial statements, the general goal of auditing traditional financial statements is: certified by Public Accountant Audit, the opinions to the audited entity's financial statements are as the following two aspects: firstly, the legality of financial statements are evaluated, that is, evaluating whether the financial statements reviewed are prepared in accordance with the applicable accounting standards and relevant accounting rules; secondly, the fairness of financial statements is assessed, scilicet assessing whether the audited financial statements fairly reflect the financial status, operating results and cash flows of the company in all major aspects. In the case of "Smart Finance" (AI Finance), the legitimacy and fairness of the preparation of financial statements evolved into the "scientific" and "reasonableness" of "financial software" and the stability and reliability of computer hardware.

From the specific objectives of the auditing financial statements, the specific audit objectives of the audit of the financial statements are generally based on the "reconfirmation" that is on the basis of the "Management's recognition of financial statements". However, In the case of "Smart Finance" (AI Finance), "Management recognition" of financial statements will gradually fade, that is to say, the management recognition that we had originally understood including the "existence and occurrence confirmation", "completeness determination", "authorization of power and obligation", "assessment of valuation and allocation", and "expression and disclosure" certification will gradually be replaced by artificial intelligence, as a result, the confirmation of responsibility of the management ,namely "accounting responsibility", will evolve into a few "manual initial accounting data collection responsibilities", and will be more "financial software development responsibilities", "software and hardware system security maintenance responsibilities," etc. Meanwhile, the CPA's "re-certification" goal will also change.

2) The Impact of "Intelligent Finance" (AI Finance) on Auditing Content

The audit object and audit content of the traditional financial statement audit are the financial statements and other relevant accounting data and assets of the audited entity. Besides, "Intelligent Finance" (AI Finance) makes the automatic generation of financial information a process of "system automatic auditing". The work of CPA is more about the understanding and identification of intelligent financial (AI financial) systems in order to review whether system presents major defects, meanwhile, the final financial information is reviewed at last, what's more the overall rationality is determined.

\section{3) The Impact of "Intelligent Finance" (AI Finance) on} Audit Process and Audit Methods

As we know, the general audit process of the CPA audit is: Establishing the audit objectives - Conducting risk assessments - Formulating audit plans - Implementing audit procedures Collecting audit evidence - Preparing audit reports. With the rapid development of "Smart Finance" (AI Finance), the contents of the audit objectives will be appropriately changed. The risk assessment needs to understand the environment, the internal control, and the business of the audited entity. It is more about understanding the adopted intelligent financial system and understanding the degree and generation of information with human intervention. As for the audit implementation, including the control test procedures such as inquiries, observations, inspections, re-execution, etc., which can be greatly simplified. Among the substantive procedures, except certification and auditing which are required by CPA, analytical procedures, recalculations, the collection of audit evidence and audit report generation that can be basically replaced by highly mature audit software (smart auditing).

\section{The StRategy OF CPAs' Auditing ChANGE Under THE BACKGROUND OF ARTIFICIAL INTELLIGENCE DEVELOPMENT.}

Given the fundamental impact of smart finance (AI Finance), auditing change of CPA must be extensive and profound. The main countermeasures are as follows:

\section{A. Adjust audit objectives of financial statement}

In general, the determination of audit objectives is mainly influenced by three factors:

Firstly, social environmental factors that enable the clarity of the audit objectives, such as court decisions and auditing standards established by accounting professional bodies. Followed by social needs which are the fundamental factors that affect the establishment of audit objectives, especially the purpose and realm which auditing accountants are needed by audit clients. Then the professional competence of the auditors that is the decisive constraints influence the establishment of audit goals.

Throughout the history of CPA, it is easy to see that the CPA audit goal has undergone four stages with the change of the audit environment. (1) A detailed audit phase with the main objective of "Error Prevention". (2) The credit audit phase with the main audit objective of "Certifying the Credit Status of Financial Statements". (3) The auditing stage of the financial statements based on the principle of "Authenticating Financial Statements and Realizing the Fairness of Errors in the Financial Statements and Falsifying the Mistakes as the main audit objectives". (4) Risk-oriented auditing stage with the purpose of "reducing information risk".

It can be said that at present, CPA audit is in the stage of "risk-oriented auditing". The accounting firm and CPA issued audit opinions on the legality and fairness of the financial 
statements on the premise of preventing and reducing the audit risk as much as possible.

However, the arrival of artificial intelligence and smart finances and changes in the socio-economic and technological environment that have inevitably led to certain changes in the auditing objectives of the CPAs. The original financial statements are compiled manually and are the result of management's determination. However, due to the rapid development of intelligent finance and the large-scale use of financial intelligent robots, the specific objectives of financial statement auditing should be to review the scientificity, rationality and stability of the financial software system, and to verify the authenticity, completeness and accuracy of the collection process of the original data, the link and degree of human involvement in the financial system, and legality and fairness of the financial statements in the end.

\section{B. Auditing Business Process Reengineering(A-BPR)}

To sum up, the audit has gone through three stages so far: traditional manual auditing, computer-assisted auditing, and intelligent auditing. It is currently in the process of moving form computer-aided auditing to smart auditing (AI auditing).

Computer-aided auditing is the use of computers as advanced tools for conducting economic supervision, verification, and evaluation. Additionally, computer-assisted auditing involves the inspection of computer-managed data and the inspection of computers that manage data. According to the opinion of the Computer Center of the Japan Accounting Institute, computer auditing has two meanings. The first is the audit of (financial) computer systems, including auditing of system installation and use costs, system and data, hardware and system environment. The second is the use of computerassisted traditional audits, establish an audit database to help accounting firms perform audits and so on.

Regard to current computer-aided auditing, although the auditing software is more and more advanced, the degree of computer involvement in the auditing process is still insufficient. The computer mainly participates in the extraction and aggregation of accounting documents, the writing of audit documents, and the generation of trial balance tables, but, data analysis ability is poor. Therefore, the current level of artificial intelligence in computer-aided auditing is still very low, and it cannot fully adapt to changes in the era of artificial intelligence.

Therefore, with the full development of artificial intelligence, coupled with the impact of "smart financial" on "smart audit", the audit process should be reformed to carry out auditing process reengineering (A-BPR), that is, " Adjustment of auditing goal-Understanding and assessing the intelligent financial system-Understanding the process of human intervention in the generation of financial information (evaluating audit risk) - AI audit plan-Implementation of AI audit procedure (The manual completion is mainly the inquiry, observation, supervision and confirmations that cannot be completed by computer) - AI audit evidence collection, identification and analysis - AI audit report - Manual review. Through A-BPR, artificial intelligence audit (AI audit) could be implemented fully.

\section{Change Human Resources Policy of Accounting Firm}

At present, under the background of the rapid development of artificial intelligence, our accounting firm should improve according to the following aspects: First, due to the obsolescence of concept, accounting firms must pay attention to the transformation of the top-down concept. Through learning and training, changing the concepts of the entire organization of accounting firm, forming a correct understanding of the urgency and importance of artificial intelligence, cloud computing, and big data, and updating relevant new technologies, new knowledge and new skills. Secondly, because of the lack of infrastructure for the intelligent auditing (AI auditing) and backward issues, including the lack of mature audit software, auditing system and audit platform, vigorously developing advanced audit software and auditing system platforms. Certainly, the solution to this problem requires the improvement and testing of the intelligent auditing (AI auditing) system platform on the one hand. On the other hand, accounting firms can also introduce $\mathrm{R} \& \mathrm{D}$ talents in artificial intelligence, organize $\mathrm{R} \& \mathrm{D}$ forces to conduct research and development, and develop auditing system platforms suitable for the audit needs of the industry instead of passively selecting and applying audit software developed by software companies. Thirdly, because of the lack of knowledge and skills of auditors, the human resources policies of accounting firms should be adjusted. Although a great number of auditors of accounting firms have relatively solid traditional audit theory and auditing skills, they lack the knowledge and skills required for intelligent auditing (AI auditing) in computers and artificial intelligence, besides, there is insufficient capacity of analysis and data screening. Also, it is possible to attract and train a large number of cross-border comprehensive audit talents who can adapt to smart audits through "external guidance" and "internal training" approaches. The fourth is to strengthen the compliance with the confidentiality principle and improve the loss of control, and to avoid the occurrence of leaks due to the use of smart auditing.

\section{Comprehensive development of intelligent audit (AI audit)}

The Big Four accounting firm claimed that "We only need high school students and robots." Since May of this year, Deloitte has taken the lead in launching financial robot products. In the middle of this year, KPMG, PricewaterhouseCoopers and Ernst \& Young also successively launched their own financial robots. Besides, PricewaterhouseCoopers, Ernst \& Young and top investment bank Credit Suisse launched high school students' projects and short-term MBA promotion projects. Therefore, modern accounting firm must vigorously develop smart auditing and establish a complete artificial intelligence auditing system (AI auditing system).

Establish AI auditing decision-support system. Decision Support System (DSS) is a kind of intelligent man-machine system which, based on management, operational research, cybernetics and behavioral science, uses computer technology, simulation technology, and information technology to address semi-structured decision problems and support decisionmaking activities. The intelligent auditing decision support system which, namely intelligent auditing system, is a software 
system formed by combining traditional auditing decision support systems with auditing expert systems and data mining systems.

Establishing an AI Audit Information Management System. Information Management System (IMS) is a comprehensive application of enterprise organization theory, accounting, statistics, etc. It is an edge technology with multiple disciplines which uses computer technology, network communication technology, and data technology in an all-round way, and at the same time IMS interacts with organizational environment, organization strategy, organizational goals, organizational structure, organizational processes and organizational culture. So IMS is not only a technical system, but also a social system. In order to carry out intelligent auditing, AI audit information management system should be established by the accounting firm. What's more, the intelligent information management system must fully be transformed and configured.

Establish AI audit centralized management and control system. The centralized management and control system (CAM) was originally used to perform unified management and control over the operation instructions and operating behaviors of the operators in the IT operation and maintenance department, and to solve the problems of "out of control operation behavior, unknown operation contents, and missing operation traces" during the IT operation and maintenance process. In order to solve the problem of secrecy control in AI auditing, an accounting firm must establish an audit centralized control system (A-CAM) and use centralized management methods to effectively manage the identity, certification, and authority of auditors, thus enabling the accounting firm to be simpler, safer, and more effective to the operation of the business. It not only maintains the security of the customer's financial information, but also ensures the effective performance of the confidentiality of the audit.

\section{CONCLUSION}

In short, the development of artificial intelligence technology will have a huge impact on the accounting profession and the accounting profession, meanwhile, it will also affect profound changes in all aspects of the audit industry in the way the "object" acts on the "subject". As a result, this has also brought unprecedented challenges to the accounting and auditing practitioners and the accounting and auditing educators. The only thing we can do is to bravely face and constantly explore progress.

\section{ACKNOWLEDGEMENT}

Stage Result of Regional Industrial Economic Development Center of Chongqing College of Electronic Engineering (number: XJPT201710)

\section{REFERENCES}

[1] Qin Rongsheng. Impact of Big Data and Cloud Computing Technology on Auditing [J].Audit research.2014 (6): 23-27.

[2] Liu Rong. Analysis of Internal Auditing Strategies in the "Big Data" Era [J].China Internal Audit.2015 (5): 42-46.

[3] Jon Raphael. See how artificial intelligence improves audit quality [J]. China Accounting News.2015

[4] Long Ziwu, Wang Yunpeng. The Impact of Big Data Era on CPA Audit Risk and Audit Quality [J]. Friends of Accounting.2016, 08:112-114.

[5] Li Xiuju. Opportunities and Challenges of CPA Audit in the Era of Big Data [J]. China Internal Audit.2015, 03:93-96.

[6] Hui Ji. Artificial Intelligence and Auditing, from the viewpoint of Ernst \& Young [J]. China's accounting vision. 2017(10).

[7] Tao Xuemei, Peng Ruifeng. Reflections on Accounting Industry in the Age of Artificial Intelligence. Accounting learning. 2017(10).

[8] Huang Liucang. Artificial Intelligence Development Challenges and Countermeasures to Accounting Work $[\mathrm{J}]$. Education Accounting Research.2017, 28(2) 